\title{
SQUAMOUS CELL CARCINOMA LUNG SECONDARY TO SQUAMOUS CELL CARCINOMA OF VAGINA WITH SUPERIOR VENA-CAVAL OBSTRUCTION MASQUERADING AS LUNG ABSCESS
}

\author{
Mahaboob Khan', Dasari. Nishanth V², V. V. Rao 3 , Sathya Prakash4, Ganapati Reddy5
}

1 Professor, Department of Pulmonary Medicine, Government General Hospital/Osmania Medical College, Erragadda, Hyderabad. ${ }^{2}$ Senior Resident, Department of Pulmonary Medicine, Government General Hospital/Osmania Medical College, Erragadda, Hyderabad. ${ }^{3}$ Assistant Professor, Department of Pulmonary Medicine, Government General Hospital/Osmania Medical College, Erragadda, Hyderabad.

${ }^{4}$ Postgraduate Student, Department of Pulmonary Medicine, Government General Hospital/Osmania Medical College, Erragadda, Hyderabad.

5 Postgraduate Student, Department of Pulmonary Medicine, Government General Hospital/Osmania Medical College, Erragadda, Hyderabad.

\section{ABSTRACT}

\section{BACKGROUND}

Primary vaginal cancer represents only $1 \%$ to $2 \%$ of malignant neoplasm of the female genital tract and squamous cell carcinoma of vagina is most common form of vaginal cancer and is usually restricted to the vagina. Rarely it metastasises to lung, liver or bone. Squamous cell carcinoma and its association with lung abscess have long being recognised. Patients presenting with symptomatic abscess have an associated malignancy in $7 \%-18 \%$ of cases. We report here a case of squamous cell carcinoma of lung secondary to primary vaginal squamous cell carcinoma with superior vena-caval obstruction masquerading as lung abscess.

\section{KEYWORDS}

Squamous Cell Carcinoma, Superior Vena-Caval Obstruction, Lung Abscess, Primary Vaginal Vault Squamous Cell Carcinoma.

HOW TO CITE THIS ARTICLE: Khan M, Nishanth DV, Rao VV, et al. Squamous cell carcinoma lung secondary to primary squamous cell carcinoma of vagina with superior vena-caval obstruction masquerading as lung abscess. J. Evolution Med. Dent. Sci. 2017;6(34):2860-2862, DOI: 10.14260/Jemds/2017/616

\section{BACKGROUND}

A 55-year-old woman, in menopause, of rural background came to our hospital with a past history of vaginal vault carcinoma of squamous cell type, successfully treated with radiotherapy came to the OPD with complaints of cough with expectoration and gradually progressing shortness of breath since 1 month. She had persistent cough with expectoration, which aggravated on lying in left lateral position without any diurnal variation. She had fever with chills intermittent type. No history of loss of weight or loss of appetite.

Examination revealed a moderately dyspnoeic patient with a respiratory rate of 24 /minute, other vital parameters being within normal limits. Pallor, digital clubbing, engorged neck veins were significant. She had puffy face without any oedema in any other location. Dilated tortuous veins were present on her anterior chest wall with flow from above to below (Figure 1). Her trachea was shifted to the right. Bronchial breath sounds of Cavernous quality were audible in the right interscapular area. Other systemic examinations yielded no positive findings.

Further workup was done with a preliminary diagnosis of lung abscess and chest x-ray (Figure 2) suggesting lung abscess with air-fluid levels in right upper and middle zones with raised right hemi-diaphragm.

Financial or Other, Competing Interest: None.

Submission 07-02-2017, Peer Review 11-04-2017,

Acceptance 19-04-2017, Published 27-04-2017.

Corresponding Author:

Dr. Mahaboob Khan,

Professor, Department of Pulmonary Medicine,

Government General Hospital/

Osmania Medical College,

Erragadda, Hyderabad-38.

E-mail: dr_mahaboob@yahoo.com

DOI: $10.14260 /$ jemds $/ 2017 / 616$

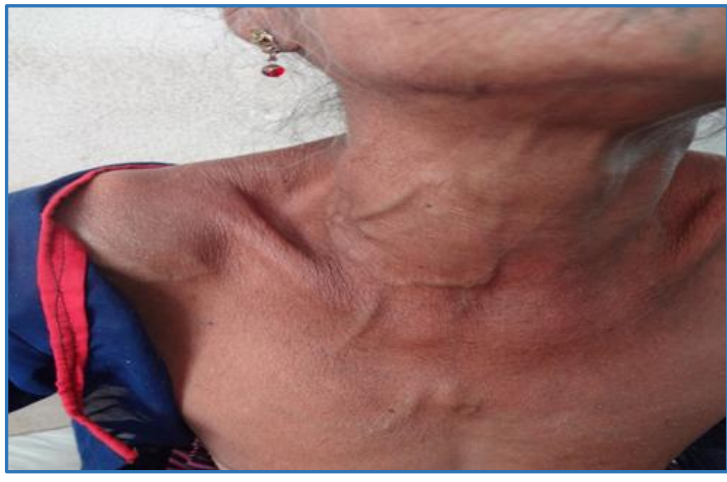

Figure 1. Dilated Torturous Veins on Anterior Chest Wall, Neck and Right Shoulder

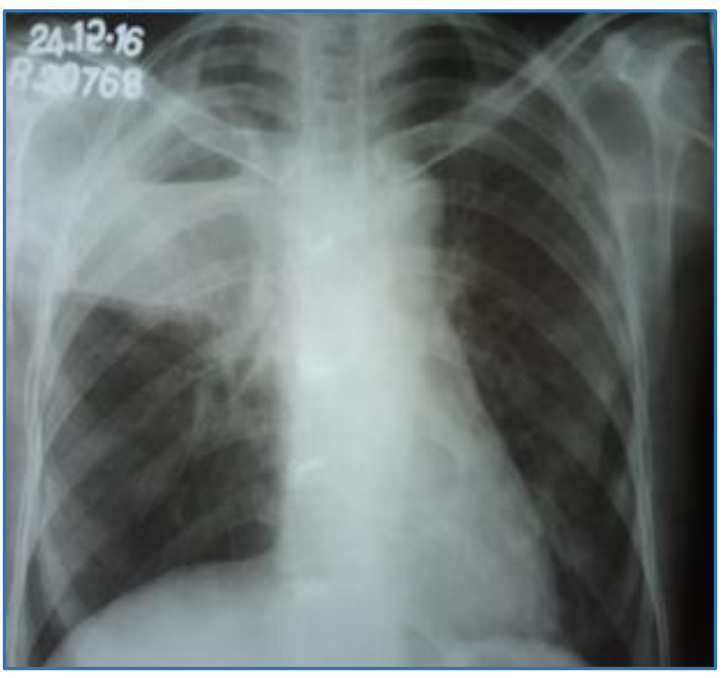

Figure 2. Chest Skiagram in PA view reveals Lesion in Right Upper Lung Field, suggestive of Lung Abscess

Investigation revealed that the patient had a normal coagulation profile with haemoglobin of $9.6 \mathrm{~g} \%$ and TLC of 
9,200 cells $/ \mathrm{mm}^{3} 78 \%$ neutrophils and ESR $100 \mathrm{~mm} /$ hour. Sputum examination revealed negative for mycobacterium tuberculosis and gram stain showing epithelial cells with gram-positive cocci in chains and few gram-negative bacilli.

The patient was diagnosed to be a case of lung abscess presenting as superior vena-caval obstruction and parenteral antibiotics were instituted. Ultrasound chest was done with a finding of consolidation of right upper lobe. Ultrasound abdomen showed no other abnormality. CT scan (Figure 3) of thorax revealed an irregular thick walled lesion with cavitation in the upper zone of the right lung and mediastinal lymphadenopathy compressing vasculature in the mediastinal window (Figure 4).
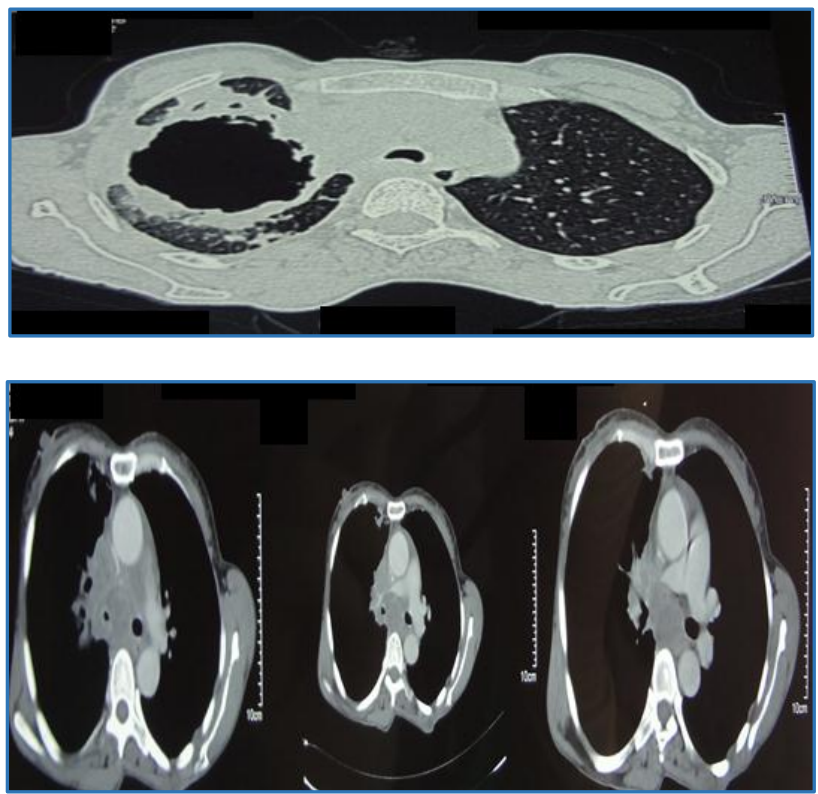

Figure 3 \& 4. CT Scan of Thorax showing Irregular Mass with Air-Fluid Level in Apical Region of Right Lung suggesting Lung Abscess and Mediastinal Lymphadenopathy with Vascular Compression

Patient was subjected to bronchoscopy (Figure 5) and an endobronchial growth in the right main stem bronchus obstructing right middle and upper lobe with purulent secretion was visualised, which was profusely bleeding on touch.

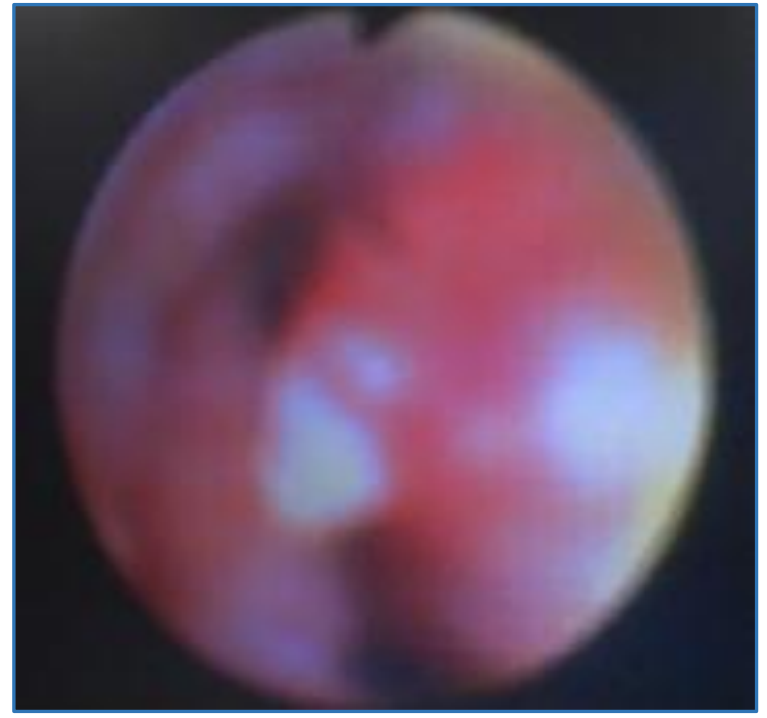

Figure 5. Bronchoscopic Picture showing Mass in Right Main Stem Bronchus
Bronchoscopic brushing and washing was sent for analysis and the histopathology (Figure 6) report revealed malignant cells in clusters of squamous type.

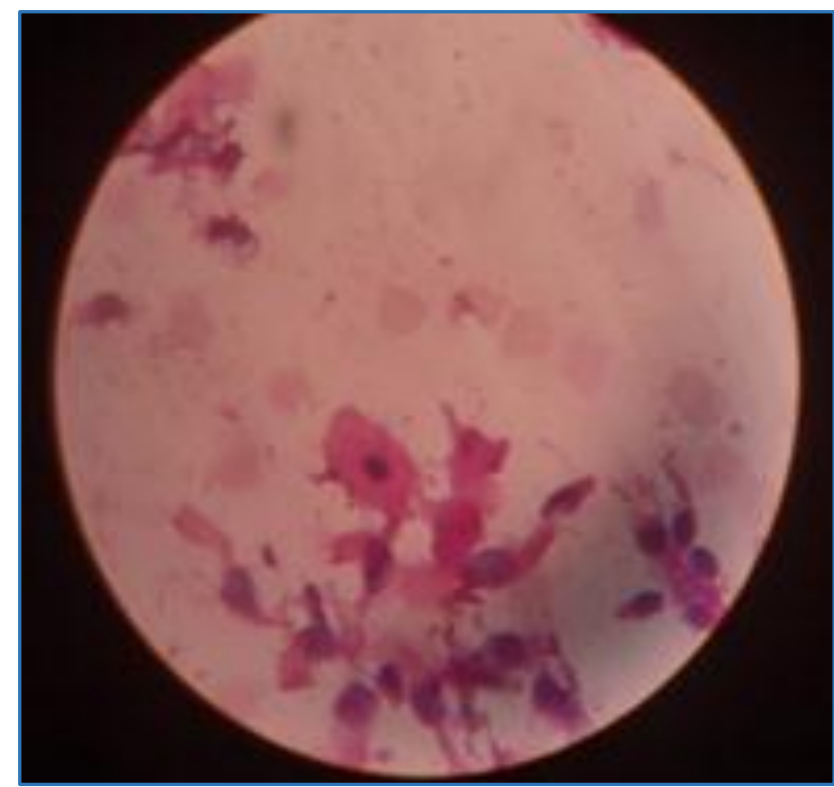

Figure 6. High Power View showing Cells with High Nucleocytoplasmic Ratio, Hyperchromatic Nuclei and abundant Thick Cytoplasm suggestive of Squamous Cell Carcinoma

The diagnosis was thus revised as a case of squamous cell carcinoma of the right lung masquerading as a lung abscess secondary to vaginal vault carcinoma causing Superior Vena Cava (SVC) syndrome. The patient was referred to our specialty oncology clinic.

\section{DISCUSSION}

Primary vaginal cancer represents only $1 \%$ to $2 \%$ of malignant neoplasm of the female genital tract. ${ }^{1}$ The mean age of patients at presentation is about 60 years. Up to $30 \%$ of patients with primary vaginal cancer have a history of in situ or invasive cervical cancer that was treated at least 5 years earlier.

Most primary tumours occur in the upper third of the vagina and are located on the posterior wall. Squamous cell carcinoma is most common in the upper anterior and lateral vaginal vaults. ${ }^{2}$ Vaginal cancer spreads by direct invasion as well as by lymphatic and haematogenous dissemination. Direct tumour spread may result in involvement of the bladder, urethra or rectum or in progressive lateral extension to the pelvic sidewall. The lymphatic drainage from the upper vagina is to the obturator, hypogastric and external iliac nodes, whereas the lower third of the vagina drains primarily to the inguino-femoral nodes. Haematogenous spread is uncommon until the disease is advanced. Owing to the relative rarity of vaginal cancer, phase III trials have not been carried out and no consensus exists regarding optimal management. Recently, Concurrent Chemoradiation Therapy (CCRT) has been suggested as a strategy to control locally advanced vaginal cancer. ${ }^{3}$

The blockage of blood flow in the SVC results in SVC syndrome. Bronchogenic carcinoma accounts for the vast majority of these cases in older adults. Patients complain of dyspnoea and a sensation of fullness in the head and/or light- 
headedness when bending over. They may also note facial swelling. Cough, pain and dysphagia are less frequent symptoms. Physical examination findings included dilated neck veins, a prominent venous pattern on the chest, facial oedema and a plethoric appearance.

The chest radiograph typically shows widening of the mediastinum or a right hilar mass. Occasionally, it may be normal. Dilated veins on the anterior chest wall and compression of the SVC may be demonstrated with CT with intravenous contrast. Because SCLC is chemosensitive, SVC syndrome due to SCLC is best treated with chemotherapy; generally, after treatment symptoms start to resolve in 5 to 7 days. NSCLC is best treated with concurrent chemoradiotherapy (see earlier discussion of treatment of stage IIIA/IIIB NSCLC). If there is a need for immediate relief of SVC obstruction, vascular stenting should be strongly considered.

Symptoms and signs of lung cancers may be considered in four general groups: (A) Those related directly to the lung tumour including cough, sputum, blood streaking from irritation, ulceration and obstruction of the bronchi; (B) Effects of extension of tumour or metastases, as superior vena cava syndrome, hoarseness and bone lesions; (C) Effects of superimposed infection or systemic symptoms and signs such as fever, chills and weight loss; and (D) Hormonal and other paraneoplastic syndromes.

Superior Vena Cava (SVC) syndrome is a known complication and presentation of lung cancer. ${ }^{4}$ However, other malignant causes like lymphomas, malignant germ cell tumours and metastatic deposits in the mediastinum as well as benign causes like central venous blockage catheter and abscess in the lungs and mediastinum have also been implicated in the causation of SVC syndrome. 5 Though not common, lung abscess has been shown to be the cause of SVC syndrome in various case reports worldwide. $6,7,8$

On the other hand, lung carcinoma and lung abscess may share similar features on chest x-rays. ${ }^{9}$ This may be due to central necrosis of a large neoplasm or post-obstruction pneumonia leading to abscess cavity formation. ${ }^{10} \mathrm{CT}$ scan of the thorax along with guided cytological/histopathological studies should enable the physician to differentiate between these two entities. ${ }^{10}$

\section{REFERENCES}

[1] Parkin DM, Bray F, Ferlay J, et al. Global cancer statistics, 2002. CA Cancer J Clin 2005;55(2):74-108.

[2] Manetta A, Pinto JL, Larson JE, et al. Primary invasive carcinoma of the vagina. Obstet Gynecol 1988;72(1):77-81.

[3] Dalrymple JL, Russell AH, Lee SW, et al. Chemoradiation for primary invasive squamous carcinoma of the vagina. Int $\mathrm{J}$ Gynecol Cancer 2004;14(1):110-7.

[4] Hyde L, Hyde CI. Clinical manifestations of lung cancer. Chest 1974;65(3):299-306.

[5] Gucalp R, Dutcher J. Oncologic emergencies. In: Fauci AS, Braunwald E, Kasper DL, et al. (eds). Harrison's principles of internal medicine. 17th edn. New York. McGraw-Hill Companies 2008.

[6] Gupta KB, Manchanda M, Chaudhary U, et al. Superior vena cava syndrome caused by pulmonary amoebic abscess. Indian J Chest Dis Allied Sci 2006;48(4):2757.

[7] Lichtenstein A, Kondo AT, Visvesvara GS, et al. Pulmonary amoebiasis presenting as superior vena cava syndrome. Thorax 2005;60(4):350-2.

[8] Kim JY, Lim CM, Koh Y, et al. A case of superior vena cava syndrome caused by klebsiella pneumoniae. Eur Respir J 1997;10(12):2902-3.

[9] Kamiya K, Yoshizu A, Misumi Y, et al. Lung abscess which needed to be distinguished from lung cancer: report of a case. Kyobu Geka 2011;64(13):1204-7.

[10] Gill R, Matsusoka S, Hatabu H. Cavities in the lung in oncology patients: imaging overview and differential diagnoses. Applied Radiology 2010;39(6):10-21. 